\title{
Exploring The Relationship of Social Media Usage and Multitasking of Social Media on Self-Efficacy and Academic Performance
}

\author{
MAHIR TAHRIR SALIH MOHAMMED \\ FARIDAH IBRAHIM \\ NORZITA YUNUS \\ Infrastructure University Kuala Lumpur
}

\begin{abstract}
Social media usage is known to harness new lifestyle among the youth. Use of social media promotes the negative as well as positive consequences for the students in general and academic life. This study examined the relationship between social media usage, multitasking of social media, and students' academic self-efficacy on students' academic performance among Malaysian youth. The current work also evaluates the mediating effect of students' academic self-efficacy on social media usage and social media multitasking on their academic performance. This study embraced a cross-sectional research design and quantitative data collected from 644 Malaysian students of higher education institutions. The collected data were analysed using SPSS v23 and PLS-SEM-based SmartPLS 3.1. The findings revealed that social media usage and social media multitasking are positively and significantly related to students' self-efficacy. Moreover, the results also showed that social media usage and multitasking, and students' self-efficacy are significantly associated with their academic performance. The results also exposed the mediational effect of students' self-efficacy on the relationship between social media multitasking and students' academic performance in higher education. The study recommends that by initiating the self-efficacy program in promoting social media's academic use and multitasking among Malaysian higher education students would result in better performance.
\end{abstract}

Keywords: Social Media, self-efficacy, multitasking, media usage, academic performance.

\section{INTRODUCTION}

The 21st century mark by the development and spread of the internet transformed life in multiple ways on earth. Social media development initiated the free flow of digital content in the shape of text and audio-visual (Anderson, 2016). Social media facilitates user content depicting opinions, interests, and ideas. Social network websites like Facebook, Twitter, Tumblr, Vine, TikTok, and Instagram are much popular among the youth (Anreassen, Pallesen \& Griffiths, 2017). The Young educated population increasingly categories as the 'digital natives' of this information-driven global world.

About $54.4 \%$ of the world population engages with the use of the internet, and the use of social media is also rising significantly. The penetration of the internet in Asia is also above $50 \%$, the penetration of the internet in Malaysia touching $80 \%$ (MCMC. 2017). The rising use of social media brings many academic advantages as well as some concerns as well. Social media is becoming a norm and for many young adults using social media becomes a crucial issue (Anreassen et al., 2017). There is also a need to address the excessive use of social media that causes many social issues among youth.

Young digital natives are taking a keen interest in using social media and academic activities, driving young higher education students' interest in social media use (Baumgartner, Weeda, Heijden \& Huizinga, 2014). Social media facilitating the general public and academic students in the execution of entrainment and academic activities (Alghamdi, Karpinski, Lepp 
\& Barkley, 2020). Some of the social media advantages are the improved communication and greater flexibility of networking, empowering collaboration for academic purposes (Kolo, Jaafar, Ahmad, 2017), the exchange of resources, remotely accessing the course material, effective preparation of the student for assignment, and allied assessments (Lau, 2017). Internet technologies facilitate educational institutions to have the learning management system for students offering flexibilities of learning and teaching remotely linked with the assessment in a comfortable manner (Muhammad et al., 2020).

The use of social media having its advantages, having particular challenges as well. Social media usage leads to unwanted social media use; students like to engage in more entertaining activities like music and games that are negatively influencing students' academic performance (Rashid, Aziz, Rahman, Saaid, \& Ahmad, 2020). Multitasking of social media activities creates less productivity and ill-efficiency of the student academic performance (Xu, Wang \& David, 2016).

Moreover, young adults are extra engaged with multitasking on social media as young adults like to consume the media content more than older adults (Carrier, Rosen, Cheever \& Lim, 2015). Media multitasking increases the mind wandering and reduces adequate attention (Alghamdi et al., 2020). The young generation is highly involved with the media multitasking and causing attention failure and reducing achievement (Lau, 2017). Absentmindedness and attention deficiency caused the severe issues of low concentration among the digital natives of the present-day generation and reports intensive use of social media as a significant cause of academic and non-academic underachievement among university-level students (Raplh, Thomson, Cheyne \& Smilek, 2013). Multitasking positively influences the higher performance among some, and some individuals cannot perform well while involved with multitasking ( $\mathrm{Wu}, 2017)$. This work aims to explore the relationship among the use of social media and social media multitasking on the student's academic self-efficacy and students' academic self-efficacy relationship with the student's academic performance.

The subsequent section of the paper deliberates the pertinent works and development of the hypothesis for the study. The next section, after the literature, summarizes the method embraced for the research work. After the research methods, analysis, and results of the research reported. The last section study provides the discussion and conclusion of the research work.

\section{LITERATURE REVIEW}

\section{a. Theoretical Stance of the Study}

Bandura (2002) postulated that psycho-social factors influence human activities. Bandura clarifies that the value of oneself significantly affects human performance. The social cognitive theory postulated that the individual self-understanding, social behaviours, and cognition of the world are interlinked (Boahene et al., 2019). Individual self-understanding or level of confidence enables one to understand and perform well in a given situation. Selfvalue or self-efficacy is the individual's perceived self and successful execution of the desired behaviour (Kolo et al., 2017). Social media use develops certain cognitive capacities that enable one to have better self-value or self-efficacy. Individuals having higher self-efficacy are better performers and achieve superior life achievements. The higher self-efficacy among the students leads to supper academic performance (Boahene et al., 2019). 
The social cognitive Theory helps explore the use of social media among higher education students, uplifting their academic self-efficacy and, in turn, academic self-efficacy related to students' academic achievement.

The threaded cognition theory evolved from the conceptualization of instantly performing multiple tasks at a time. The individual gets engaged in different goals or objectives that are interlinked and triggers the human's perceptual, motor, and procedural activities (Salvucci \& Tattgen, 2008). Threaded cognition theory suggests the multitasking of actions represented as the multiple threads connected with each other managed by the human brain. Theory of threaded cognition employed as the base for estimating human cognition and behaviours (Bellur et al., 2015). A human develops certain sub-objectives and comparable cognitive threads required to achieve multiple objectives like academic achievement among higher education students (Xu et al., 2016). Humans can perform numerous tasks at a time, like walking and talking (Salvucci \& Tattgen, 2008). Social media use and multitasking are understood well with the help of threaded cognition theory.

\section{b. Social Media Usage in Education}

Development in IT influences the use of technology in education. With the recent development of web2.0, social media-based content increasingly adopted and used in learning institutions and two-way technology-based communication (Ross, Perkins \& Bodey, 2016). Social media, in a way, revolutionizing the ways of teaching and learning. Social media use among higher education students improves learning with the student's collaborative activities in a virtual learning environment (Morissan, 2020). In one-way, social media use in education transforms traditional means of learning and teaching with the new paradigm where only educational institutions are privileged to deliver the knowledge to the students (Lau, 2017). Multiple sources of knowledge have become available with the advent of social media, and more people are offering free or paid knowledge-based content on the different social media platforms (Xu et al., 2016).

\section{c. Academic Performance}

Academic performance is achieving the specific academic targets under the students' educational setting in a particular college or university (Boahene, Fang \& Sampong, 2019). Academic performance also described as learning outcome achieved, rating in assessment, test scores, and GPA to measure the student's academic performance (Alghamdi et al., 2020). Student development of reasoning skills, self-adequacy, improvement in the subject, and non-psychological progression also regarded as the student's academic performance (Drago, Rheinheimer \& Detweiler, 2018).

\section{d. Academic Self-Efficacy}

Individual self-efficacy is the perceived ability to perform or behave in a particular manner. Self-efficacy also describes the individual self-confidence to behave and execute specific achievements under consideration (Bandura, 2001). Student's level of academic self-efficacy perceived as the student's level of self-certainty to achieve the particular academic achievement in assignments, midterms, course work, and year-end results (Arbona, 2016). Students' academic self-efficacy related to self-planned learning and academic achievements among Korean students (You, 2018). Academic self-efficacy promotes the self-control that 
leads to better accomplishment of educational objectives in terms of learning, enhancing academic skills, and overall academic performance (Boahene et al., 2019).

\section{a. Social Media Usage}

\section{FACTORS RELATED TO THE STUDENTS' SELF-EFFICACY.}

The use of social media is becoming the norm among young adults (MCMC, 2017). Social media usage enables young adults and students of higher educational institutions to acquire the right and useful information with young fellows' cooperation (Boahene et al., 2019). Social media use gain attention among scholars and academic communities to enhance students' academic motivation using technology, where knowledge sharing, collaboration, and interaction among fellow students may facilitate the students' learning-oriented activities (Hassell \& Sukalich, 2016). Social media promotes collaborative learning and improves students' self-perception that they can access all relevant information required in higher education (Andreaseen et al., 2017). Academic challenges develop social media's information attitude and access the right and prevalent information to uptake academic life challenges (Boahene et al., 2019). Access and the proper use of social media are related to healthy selfefficacy (Hassell \& Sukalich, 2016). Taking a note from the above discussion, we forward the following hypothesis:

Hypothesis (H1): Social media usage among higher education students positively related to the students' academic self-efficacy.

\section{b. Multitasking on Social Media}

Multitasking relates to the entrainment driven or relates to having a good time concentrating on anything specific (Chang, 2017). Many students think multitasking improves their skills to handle many tasks effectively in the classroom or outside of the classroom (Carrier et al., 2015). Students engage in multitasking, as multitasking saves time, and one can perform tasks at hand accurately (Dindar \& Akbulut, 2016). Distraction is natural during multitasking, and significant results may not achieve for all students. Technology also fosters multitasking, as students engage in learning and listening to music or texting as well (Chang, 2017). Social media multitasking for academic purposes positive impact on student self-efficacy (Wu, 2017). The improved social media multitasking promotes the self-worth and perceived individual capacity to perform academic activities effectively (Boahene et al., 2019). Based on the above discussion, we like to forward the following hypothesis:

Hypothesis ( $\mathrm{H} 2)$ : Social media multitasking usage among higher education students positively related to the students' academic self-efficacy.

\section{FACTORS RELATED TO STUDENTS' ACADEMIC PERFORMANCE}

\section{a. Social Media Usage}

Among the undergraduate students, social media's use positively related to self-learning improves the self-assessment and motivation towards learning and academic performance (Liu, Kirshner \& Karpinski, 2017). Kaya and Bicen (2016) reported that the student's use of social media negatively influences the students' academic performance. However, literature documented that unnecessary and unmonitored heavy use of social media distracts the students from the educational activities toward more entertaining non-academic activities 
(Kolo et al., 2017). These counterproductive social media use lead to less academic success for the students (Lambic, 2016). Students spending more time on social media have a lower GPA than the student spending less or no time on social media (Lau et al., 2017). However, university students' use of social media for academic reasons positively influences the student's academic performance (Kolo et al., 2017). Taking the insights from the discussion, as mentioned earlier, we forwarded the following hypothesis:

Hypothesis $\left(\mathrm{H}_{3}\right)$ : Social media usage among higher education students positively related to the students' academic performance.

\section{b. Multitasking on Social Media}

Multitasking is natural to human beings and acknowledged as mutually executing two to more activities simultaneously (Wu, 2017). Multitasking is the comprehensible amplification of running two or more tasks simultaneously. Media multitasking manifold increased among young adults due to access to computers, smartphones, and smart handheld tablets. Media multitasking influences cognitive functions and negatively related to academic performance (Xu et al., 2016). Social media multitasking refers to utilizing one or more social media sites while taking an active part in social media and non-media activities ( $\mathrm{Wu}, 2017)$. The abovecited discussion prompts us to forward the following hypothesis:

Hypothesis $\left(\mathrm{H}_{4}\right)$ : Student social media multitasking positively related to the students' academic performance.

\section{c. Students' Academic Self-Efficacy}

Based on Bandura's (2001) conceptualization, academic self-efficacy is the student's selfbelief to perform well in educational activities. Previous scholarship profoundly documented the relationship between self-efficacy and the academic performance of the students. Boahene et al. (2019) documented that higher education students' academic self-efficacy positively influences academic performance among Ghana students. The above discussion facilitates us to propose the following hypothesis:

Hypothesis $\left(\mathrm{H}_{5}\right)$ : Student academic self-efficacy significantly related to students' academic performance.

\section{MEDIATING EFFECT OF STUDENT ACADEMIC SELF-EFFICACY}

Social media usage is good for the student's intellectual appetite (Boahene et al., 2019). However, unnecessary and excessive social media use leads to undesirable behavioural outcomes like a waste of time and resources and guides to unavoidable social behaviours (Lambic, 2016). Individual self-efficacy helps control social media's unnecessary usage and empowers students to effectively use social media (Ross et al., 2016).

Moreover, the higher level of social media multitasking keeps the student engaged in unwanted and avoidable tasks, bringing no benefits to their academic performance (Xu et al., 2016). The unwanted misuse of multitasking on social media curtailed improving individual self-efficacy (Zhen et al., 2017). With a higher level of individual self-efficacy, student perceived control improved, and student concentrates more on the actual task at hand (Ross et al., 2016). The proper use of social media multitasking enhances students' tasks and 
focuses more on the primary educational task (Raplh et al., 2013). The student with a higher level of self-efficacy performs well in social media multitasking and focus more on the objective task at hand and least concerted with the other subjective educational or noneducational tasks over social media.

The above discussion prompts us to forward the following hypothesis:

- Hypothesis (HM1): Student academic self-efficacy mediates the relationship between social media usage and students' academic performance.

- Hypothesis (HM2): Student academic self-efficacy mediates the relationship between the students' social media multitasking and academic performance.

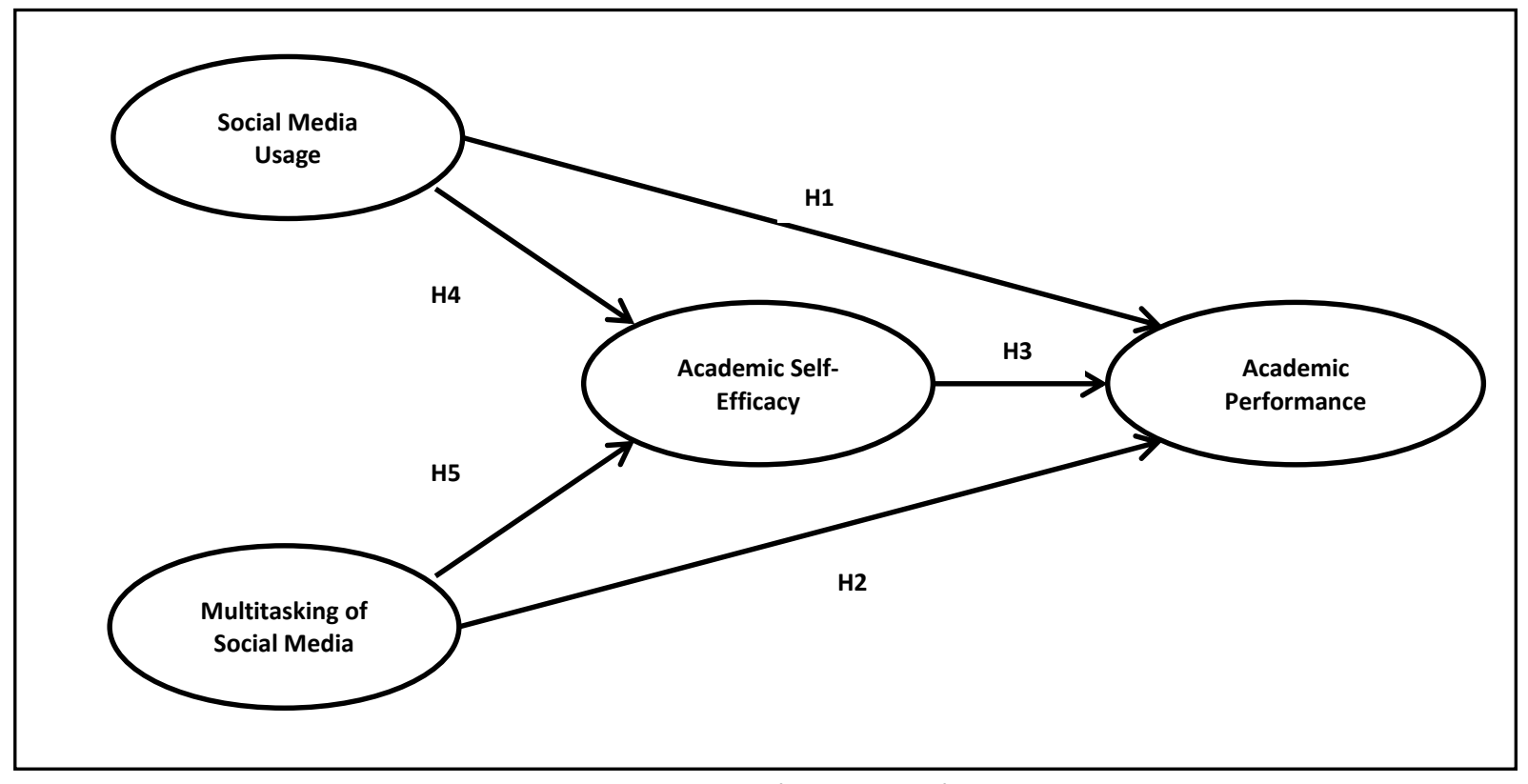

Figure 1: Research Framework

\section{a. Data Collection and Study Sample Design}

\section{RESEARCH METHODOLOGY}

Research design paves the way to achieve the research objectives by setting the research procedure to collect and analyze data. Our current work has a survey-based quantitative design, which is much standard in social science research. We target Malaysian higher education students. As reported by the Malaysian Qualification Registrar (MQR) website, five public and 32 institutes of higher education institutions located in Selangor, Malaysia. In Selangor are two cities shortlisted, i.e., Shah Alam and Serdang; these two cities have public and private higher education institutions than other cities in the state. We are looking for suitable respondents using social media and students of a higher education institution. Therefore, we select Serdang city as the highest number of internet users belongs to the Serdang city (MCMC, 2017). Two universities identified to collect data; one was a public university and one private, i.e., Universiti Putra Malaysia and Perdana Universiti. Having no access to the sampling frame, non-probability convenience sampling performed for the study. To perform the data analysis in PLS-SEM, the sample must be ten times the study paths (Hair, Risher, Sarstedt \& Ringle, 2019). Krejcie and Morgan's (1970) table utilized to evaluate the 
sample's number for the data analysis. A total of 644 respondents recruited during data collected from March 2019 to August 2019.

\section{b. Survey Instrument}

A questionnaire with six sections developed for the study. Section A of the questionnaire has five-question items identifying the demographics of the study respondents. Section B carried seven questions about the use of social media. Section $C$ has 17 questions items asked to evaluate social media usage among higher education students. Nine items formulate section $D$ relates to social media multitasking among the study respondents. Section E contains eight items inquiring about the student's self-efficacy, the last section $F$ have the eleven question items asked to evaluate the students' academic performance. All the responses estimate on the five-point Likert scale.

Table 1: Survey Instrument

\begin{tabular}{lll}
\hline \multicolumn{1}{c}{ Variable } & Items & Source \\
\hline Social media usage & 17 & Bellur et al., 2015; Jenkins-Guarnieri et al., 2013 \\
Multitasking of Social media & 9 & Bellur et al., 2015; Lau, 2017, David et al., 2015 \\
Student self-efficacy & 8 & Bellur et al., 2015; Schaufeli et al (2002); Wu (2017) \\
Student academic performance & 11 & $\begin{array}{l}\text { Liu et al., (2005); Martha (2010); Roy (2011); Tan \& } \\
\text { Yates (2007) }\end{array}$ \\
\hline
\end{tabular}

\section{c. Assessment of Common Method Variance (CMV)}

$\mathrm{CMV}$ issue is normal in social science research, chiefly triggered by the data collection methods and techniques (Podsakoff, Mackenzie Lee \& Podsakoff, 2003). Harman's (1976) one-factor test was suggested as an approach to estimate the impact of CMV on the study constructs (Podsakoff et al., 2003). One-factor Harman's test approves that CMV is not a critical matter for study as the main factor account for $49 \%$ variance and less than the recommended limit of 50\% (Podsakoff et al., 2003).

\section{d. Data Analysis Method}

Partial least squares structural equation modelling (PLS-SEM) utilized with the Smart-PLS software 3.1 for data analysis. PLS-SEM is a multivariate analysis instrument to gauge the path models having latent constructs with composites (Hair et al., 2019). PLS-SEM empowers the researcher to tackle the non-normal and small data sets. Furthermore, PLS-SEM has a casualpredictive nature with an undisturbed supposition of goodness-of-fit estimation than the covariance-based SEM (Chin, 2010). Two-step techniques employed for data analysis with PLS-SEM. The first measurement was performed on the model to test the model's reliability and validity at the constructs' level (Hair et al., 2019). The second stage executed to estimate the structural model and investigate the study hypotheses with significance levels (Chin, 2010). Model estimation performed with $r^{2}, Q^{2}$ and the effect size $f^{2}$ describes the exogenous construct's path effect for the endogenous construct (Hair et al., 2019). 


\section{a. Demographic Characteristics}

\section{DATA ANALYSIS}

In the study, $80 \%$ of the study respondents were female, and $20 \%$ were male. Study respondents aged $22-23$ years old were $41.3 \%$; $20-21$ years old were $39.4 \%$; $24-25$ years were $19.7 \%$; above 25 were $1.3 \%$, and the remaining were $18-19$ years old. The majority of the respondents' enrolled with public higher education institutions $(68.9 \%)$ while $31.1 \%$ were from a private university. Majority of the respondents pursuing the education in Science course (27.8\%) followed by $21.4 \%$ in Medicine courses, $20.2 \%$ in Management course, $18.5 \%$ in Art education and remaining $12.1 \%$ had registered in Engineer related courses.

About $28.2 \%$ of the respondents used more than five social media sites, while $26.2 \%$ and $18.6 \%$ of them used five and four social media sites, respectively. Only a small percentage of respondents using less than three social media sites. In term of duration of media site use, $48 \%$ of the study respondents used social media sites for more than 180 minutes in a day, followed by $26.2 \%$ used for $60-120$ minutes per day, $17.9 \%$ used for $120-180$ minutes, $6.2 \%$ used for 30-60 minutes and the remaining used less than 30 minutes in a typical day (Table 2).

Table 2: Demographic Characteristics $(n=644)$

\begin{tabular}{|c|c|c|c|c|c|}
\hline & $\mathbf{N}$ & $\%$ & & $\mathbf{N}$ & $\%$ \\
\hline Gender & & & \multicolumn{3}{|l|}{ Institution } \\
\hline Male & 129 & 20.0 & Public & 444 & 68.9 \\
\hline Female & 515 & 80.0 & Private & 200 & 31.1 \\
\hline \multicolumn{3}{|l|}{ Age Group } & \multicolumn{3}{|l|}{ Degree Program Courses } \\
\hline $18-19$ years & 6 & 0.9 & Art & 119 & 18.5 \\
\hline 20-21 years & 254 & 39.4 & Engineering & 78 & 12.1 \\
\hline $22-23$ years & 266 & 41.3 & Management & 130 & 20.2 \\
\hline $24-25$ years & 127 & 19.7 & Medicine & 138 & 21.4 \\
\hline Above 25 years & 21 & 1.3 & Science & 179 & 27.8 \\
\hline \multicolumn{3}{|c|}{ Type of social media site used* } & \multicolumn{3}{|c|}{ Number of social media sites used } \\
\hline WhatsApp & 633 & 98.3 & 1 & 63 & 9.8 \\
\hline Instagram & 547 & 84.9 & 2 & 58 & 9.0 \\
\hline YouTube & 531 & 82.4 & 3 & 53 & 8.2 \\
\hline Facebook & 400 & 62.1 & 4 & 120 & 18.6 \\
\hline Twitter & 287 & 44.6 & 5 & 168 & 26.2 \\
\hline Snap chat & 118 & 18.3 & $5+$ & 182 & 28.2 \\
\hline Others & 137 & 21.3 & & & \\
\hline \multicolumn{3}{|c|}{ Time spent on social media per day } & \multicolumn{3}{|c|}{ Time of accessing Social media* } \\
\hline Less than 30 minutes & 11 & 1.7 & During free time & 585 & 90.8 \\
\hline Between 30-60 mins & 40 & 6.2 & In spare moment & 483 & 75.0 \\
\hline Between $60-120$ mins & 169 & 26.2 & In mealtimes & 269 & 41.8 \\
\hline Between 120-180 mi & 115 & 17.9 & When at school & 214 & 33.2 \\
\hline More than 180 mins & 309 & 48.0 & During social occasion & 205 & 31.8 \\
\hline
\end{tabular}

\section{b. Reliabilities and Validities}

Following the authorization from Hair et al. (2019), reliability for the study's latent constructs was achieved and assessed by Cronbach's alpha (CA) and composite reliability (CR). Cronbach's alpha values for all constructs are well above the inception of 0.70 , and the 
minimum value of Cronbach's alpha value achieves 0.825 (Chin, 2010). The results represented in Table 2. Besides, $C R$ values were well beyond the threshold of 0.70 , where the lowest value of CR value was 0.873 (Chin, 2010). These outcomes indicate that the latent constructs recognized appropriate reliabilities and executed well for further analysis. The average variance extracted (AVE) for all items for each construct must be above than 0.50 score to the extent the satisfactory convergent validity to support the uni-dimensionality concept for each construct (Hair et al., 2019). Items display that each construct has adequate convergent validity (see Table 2.). The item loading confirmed the construct discriminant validity and depicted in Tables 3 and 4, respectively.

Table 3: Reliability and Validity

\begin{tabular}{lcccccc}
\hline Variables & No. Items & Mean & SD & CA & CR & AVE \\
\hline SMU & 14 & 3.19 & 0.88 & 0.937 & 0.946 & 0.559 \\
MTS & 8 & 2.78 & 0.80 & 0.903 & 0.921 & 0.596 \\
SSE & 5 & 3.19 & 0.63 & 0.846 & 0.890 & 0.620 \\
SAP & 6 & 2.74 & 0.55 & 0.825 & 0.873 & 0.537 \\
\hline
\end{tabular}

Note: SMU: Social media usage; MTS: Multitasking on Social media; SSE: Student Self-Efficacy; SAP: Student academic Performance; SD: Standard Deviation; CA: Cronbach's Alpha; DG rho - Dillon-Goldstein's rho; CR Composite Reliability; AVE - Average Variance Extracted; VIF - Variance Inflation Factors

Table 4: Discriminant Validity

\begin{tabular}{lcccc}
\hline & Table 4: Discriminant Validity & & SSE & SAP \\
\hline Fornell-Larcker Criterion & SMU & & & \\
SMU & & & & \\
MTS & $\mathbf{0 . 7 4 7}$ & $\mathbf{0 . 7 7 2}$ & $\mathbf{0 . 7 8 7}$ & \\
SSE & 0.475 & 0.475 & 0.317 & $\mathbf{0 . 7 3 3}$ \\
SAP & 0.293 & 0.460 & \\
\hline
\end{tabular}

Note: SMU: Social media usage; MTS: Multitasking on Social media; SSF: Student Self-Efficacy; SAP: Student academic Performance.

All the study constructs have suitable discriminant validities (See Table 3.). Additionally, the Fornell-Larcker criterion (1981) employed to accomplish the discriminant validity of each study constructs. Fornell-Larcker criterion assessed with the square root of the respective construct's AVE, and the square root of AVE for the construct must be greater than the correlation among the other constructs (Hair et al., 2019). Table 4 \& 5 shows that the study has adequate discriminant validity for each construct.

Table 5: Loadings and Cross-Loading

\begin{tabular}{|c|c|c|c|c|}
\hline Code & SMU & MSM & AHF & SBN \\
\hline SMU - Item 1 & 0.812 & & & \\
\hline SMU - Item 2 & 0.797 & & & \\
\hline SMU - Item 3 & 0.802 & & & \\
\hline SMU - Item 4 & 0.672 & & & \\
\hline SMU - Item 5 & 0.635 & & & \\
\hline SMU - Item 6 & 0.623 & & & \\
\hline SMU - Item 7 & 0.742 & & & \\
\hline SMU - Item 8 & 0.715 & & & \\
\hline SMU - Item 9 & 0.759 & & & \\
\hline SMU - Item 10 & 0.771 & & & \\
\hline SMU - Item 11 & 0.752 & & & \\
\hline SMU - Item 12 & 0.804 & & & \\
\hline
\end{tabular}




\begin{tabular}{|c|c|c|c|c|}
\hline SMU - Item 13 & 0.748 & & & \\
\hline SMU - Item 14 & 0.796 & & & \\
\hline MSM - Item 1 & & 0.681 & & \\
\hline MSM - Item 2 & & 0.620 & & \\
\hline MSM - Item 3 & & 0.734 & & \\
\hline MSM - Item 4 & & 0.896 & & \\
\hline MSM - Item 5 & & 0.770 & & \\
\hline MSM - Item 6 & & 0.877 & & \\
\hline MSM - Item 7 & & 0.791 & & \\
\hline MSM - Item 8 & & 0.770 & & \\
\hline SSE - Item 1 & & & 0.716 & \\
\hline SSE - Item 2 & & & 0.833 & \\
\hline SSE - Item 3 & & & 0.798 & \\
\hline SSE - Item 4 & & & 0.805 & \\
\hline SSE - Item 5 & & & 0.779 & \\
\hline SAP - Item 1 & & & & 0.608 \\
\hline SAP - Item 2 & & & & 0.650 \\
\hline SAP - Item 3 & & & & 0.799 \\
\hline SAP - Item 4 & & & & 0.784 \\
\hline SAP - Item 5 & & & & 0.699 \\
\hline SAP - Item 6 & & & & 0.829 \\
\hline
\end{tabular}

\section{c. Model Goodness of Fit with the Standardized Root Mean Square Residual (SRMR)}

Following the direction recommended by Hair et al. (2019), the study model Goodness of Fit evaluated the SRMR index. A model regarded as fir when the value of SRMR value below the value of 0.08 . For the current model, the SRMR value achieves a value of 0.078 . The results show that the current model has a good fit.

\section{d. Path Analysis}

Subsequently, having the acceptable reliabilities and validities from the structural assessment of the study model. The next measurement assessment achieves to examine the study hypothesis. The adjusted $r^{2}$ value for the two exogenous constructs (i.e., social media usage and multitasking of social media) on the student's self-efficacy explains the 22.9 percent of change in the student's self-efficacy. The predictive relevance $\left(\mathrm{Q}^{2}\right)$ value for the part of the model is 0.141, indicating a small predictive relevance (Chin, 2010). The adjusted $r^{2}$ value for the exogenous construct (i.e., students' self-efficacy) on the students' academic performance reveals the percent 22.6 of change in students' academic performance. The predictive relevance $\left(Q^{2}\right)$ value for the part of the model is 0.115 indicating a small predictive relevance (Chin, 2010).

Model standardized path values, t-values, and significance level illustrated in table 5. The path coefficient between SMU and SSE $(\beta=0.087, \mathrm{t}=2.083, p=0.037)$ indicates a significant and positively related social media usage on the student self-efficacy. The result offers substantial statistical sustenance for the H1. The path value for the MTS and SSE $(\beta=$ $0.436, t=11.057, p=0.000$ ) shows the impact of social media multitasking positively and significantly on student self-efficacy the Malaysian students of higher education, accordingly offers significant statistical backing for the $H 2$. The path between SMU and SAP $(\beta=0.096, t$ $=1.901, p=0.025)$, demonstrating the relationship among the student social media usage 
and students' academic performance, come positive and significant; it delivers the validation to support the H3. The path between MTS and SAP $(\beta=0.362, t=8.244, p=0.000)$, indicating the relationship among the multitasking of social media and students' academic performance, is positive and significant; it provides the support to accept the H4. The path between SSE and SAP $(\beta=0.119, t=2.480, p=0.016)$, signifying the relationship among the student academic self-efficacy and students' academic performance, arise positive and significant; it delivers the endorsement to support the H5. Table 6 shows the path coefficients.

Table 6: Path Coefficients

\begin{tabular}{|c|c|c|c|c|c|c|c|c|c|c|}
\hline Hypo & & Beta & $\begin{array}{l}\mathrm{Cl}- \\
\mathrm{Min}\end{array}$ & $\mathrm{Cl}-\mathrm{Max}$ & $T$ & $p$ & $f^{2}$ & $r^{2}$ & $\mathbf{Q}^{2}$ & Decision \\
\hline \multicolumn{11}{|c|}{ Factors affecting the Student Self-efficacy } \\
\hline $\mathrm{H}_{1}$ & $\mathrm{SMU} \rightarrow \mathrm{SSE}$ & 0.087 & 0.030 & 0.170 & 2.083 & 0.037 & 0.190 & 0.229 & 0.141 & Accept \\
\hline $\mathrm{H}_{2}$ & $\mathrm{MTS} \rightarrow \mathrm{SSE}$ & 0.436 & 0.350 & 0.500 & 11.057 & 0.000 & & & & Accept \\
\hline \multicolumn{10}{|c|}{ Factors affecting the Student Academic } & \\
\hline $\mathrm{H}_{3}$ & $\mathrm{SMU} \rightarrow \mathrm{SAP}$ & 0.096 & 0.014 & 0.117 & 1.901 & 0.025 & 0.014 & & 0.115 & Accept \\
\hline $\mathrm{H}_{4}$ & $\mathrm{MTS} \rightarrow \mathrm{SAP}$ & 0.362 & 0.335 & 0.489 & 8.244 & 0.000 & & & & Accept \\
\hline $\mathrm{H}_{5}$ & $S S E \rightarrow$ SAP & 0.119 & 0.019 & 0.216 & 2.480 & 0.016 & & 0.226 & & Accept \\
\hline
\end{tabular}

Note: SMU: Social media usage; MTS: Multitasking on Social media; SSE: Student Self-Efficacy; SAP: Student academic Performance Source: Author's data analysis

\section{e. Mediation Analysis}

Student's self-efficacy's mediational effect on the relationship among the student social media usage and academic performance tested with the hypotheses HM1. The result discloses that the student's self-efficacy does not mediate the relationship between SMU and SAP ( $B=$ $0.010, \mathrm{Cl} \min =0.001, \mathrm{Cl} \max =0.024, p=0.103$ ) and offers no support for the hypothesis HM1. Hypothesis HM2 proposes the relationship among the MTS and SAP mediated by the SSE. The result portrays that students' self-efficacy mediates the relationship between MTS and SAP $(B=0.052, \mathrm{Cl} \min =0.008, \mathrm{Cl} \max =0.098, p=0.022)$, and provides support for the hypothesis HM2. The mediation results presented in Table 7.

Table 7: Mediating Effects

\begin{tabular}{llcccccc}
\hline Hypo & Associations & Beta & $\mathbf{C l}-$ Min & $\mathbf{C l}-$ Max & $\boldsymbol{t}$ & $\boldsymbol{p}$ & Decision \\
\hline $\mathrm{HM} 1$ & $\mathrm{SMU} \rightarrow \mathrm{SSE} \rightarrow \mathrm{SAP}$ & 0.010 & 0.001 & 0.024 & 1.646 & 0.103 & Reject \\
$\mathrm{HM} 2$ & $\mathrm{MTS} \rightarrow \mathrm{SSE} \rightarrow \mathrm{SAP}$ & 0.052 & 0.008 & 0.098 & 2.358 & 0.022 & Accept \\
\hline
\end{tabular}

Note: SMU: Social media usage; MTS: Multitasking on Social media; SSF: Student Self-Efficacy; SAP: Student academic Performance. Source: Author's data analysis

\section{DISCUSSION}

\section{a. Social Media Usage \& Multitasking of Social Media Related to Student Self-Efficacy} The study's first two hypotheses move to appraise the SMU and SSE relationship between the MTS and SSE. The study findings supported the argument that Malaysian students' social media usage has significantly related to students' self-efficacy. Study findings are parallel to Boahene et al. (2019) findings that social media usage influences academic self-efficiency among Chinese students. Furthermore, the study findings also confirm the significant relationship among the MTS and SSE. The findings of this study coincide with the results postulated by Lau et al. (2017). 


\section{b. Social Media Usage \& Multitasking of Social Media Related to Student Academic Performance}

The study's next two hypotheses proposed the SMU and SAP relationship and the MTS and SAP. The study findings supported the argument that social media usage among Malaysian students considerably positively linked to their academic performance. Our study outcomes correspond to the finding proposed by Boahene et al. (2019), that the student use of social media for academic reasons linked with the students' superior academic performance. Furthermore, the study result also approves the significant positive connection that exists between the MTS and SAP. Current study findings are consistent with the result showed by Alghamdi et al. (2020) that multitasking on social media positively links with students' academic performance in higher education.

\section{c. Student Self-Efficacy and Student Academic Performance}

The next objective proposed in this study was to evaluate the relationship between SSE and SAP. The study findings supported the hypothesis that the student's academic self-efficacy significantly related to the students' academic performance. Study findings are parallel to Kolo et al. (2017) 's findings that the student with higher self-efficacy has higher academic results.

\section{d. Mediating Effects of Student Self-Efficacy}

The next mediating effect of SSE assesses with two mediation hypotheses HM1 and HM2. For the HM1, the finding shows no meditating effect of SSE for the relationship between the SMU and SAP among the Malaysian youth. The results of the current study contrast with Hassell and Sukalich (2016) which the authors found that students' self-efficacy significantly mediates the inversed relationship between general use of social media and academic performance among higher education students. The insignificance found in the current study may be due to the existing significant positive relationship between SMU and SAP, which do not possess any mediating effect even with SSE. The HM2 hypothesizes the significant mediating impact of the SSE between the MTS and SAP. The finding proves the SSE's meditating effect for the relationship between the MTS and SAP among the Malaysian higher education students. The current study's findings strengthen by the work of Alghamdi et al. (2020), who reported a similar finding.

\section{CONCLUSION}

Young students increasingly engage with the use of social media for academic and nonacademic purposes. The current work scrutinizes the relationship between the student's social media uses, multitasking on social media related to the student's self-efficacy, leading to the student's academic performance. The study also explores the mediating effect of students' self-efficacy on social media usage and multitasking on social media with student academic performance among Malaysian higher education students.

The results establish a significant positive relationship of social media usage and social media multitasking with students' self-efficacy. Besides, social media usage, social media multitasking, and students' self-efficacy show a significant positive relationship with students' academic performance. The student's self-efficacy significantly mediates the relation of students' academic performance with social media multitasking but not with social media usage. 
Higher education students are using social media for academic as well as nonacademic purposes. The proper use of social media for academic reasons upsurge student self-efficacy and academic performance. Students gain readily, and reliable information improves the students' efficacy (Andreassen et al., 2017). Improvements in self-efficacy drive the students' academic achievement level in the short and long term (Zhen et al., 2017). However, overuse or misuse of social media causes the students' non-productive activities that may improve the students' self-efficacy but not affect students' academic performance (Andreassen et al., 2017; Xu et al., 2016).

Study findings offer several implications for developing effective strategies for improving the student's self-efficacy and academic performance. The consequence of social media usage and multitasking on social media is positively related to enhancing the student's level of self-efficacy and improving the student's academic performance. Such self-efficacy enhancing programs must initiate that direct the student for the appropriate use of social media. Academic staff must take note of the heavy use of social media among their respective students. Student peers can help the management of social media usage as well. However, it is essential to note that higher self-efficacy may not lead to positive academic performance (Hassell \& Sukalich, 2016). Among the students, the lack of interest in academic performance also needs to highlight. Students with much higher self-efficacy consider academic achievement, not a true reflection of students' talent (You, 2018). Learning not only happens in academic settings but also in non-academic settings (Zhen et al., 2017). Furthermore, task difficulty, the task's value, and expectancy of target achievement also motivate the task's performance at hand (You, 2018). Therefore, it is crucial to understand the students' academic and non-academic performance with the use of social media and multiple tasking on social media.

The study has the relevant three limitations, the study analysis performed on the quantitative cross-sectional data having limited generalizability. Future research considers collecting longitudinal data to fully explore social media usage and multitasking, affecting the students' academic performance. Secondly, the self-efficacy scores may vary in different semesters in higher education related to the students' academic achievements. However, the study model can explore social media usage and multitasking on each student's academic achievement. The perceived individual personality factors may utilize to explore the effective or ineffective use of social media for students' academic performance. Future studies need to incorporate the personal factor affecting social media usage and students' academic performance. This study contributes to the management of students' use of social media for educational purposes. The overuse of social media and social media multitasking negatively influences the student's academic performance. Future research work may evaluate the role of perceived stress of academic life on the misuse of social media that may have a negative effect on the students' academic performance. Lastly, work estimates the general academic performance of a student in higher education, which limits the generalization of the findings. Future studies may compare academic and non-academic performance with the use of social media among students. 


\section{BIODATA}

Mahir Tahrir Salih Mohammed is a PhD student in Communication at Faculty of Business, Information \& Human Sciences (FBIHS), Infrastructure University Kuala Lumpur (IUKL). His research interests are Media and Education, Media Management, Social Media and Communication. Email: mahirtahrir@gmail.com

Faridah Ibrahim is a Professor at the Department of Communication, Faculty of Business, Information \& Human Sciences (FBIHS), Infrastructure University Kuala Lumpur (IUKL). She is currently the Head of Postgraduate Programme (Communication). She obtained her PhD in Journalism and Organisational Communication at University Putra Malaysia and University of Minnesota Twin Cities, USA. Her research interests are Peace and War Journalism, Media Management and Gender, Professionalism and Ethics, and Organisational Communication. Email: faridah@iukl.edu.my

Norzita Yunus is Dean, Centre for Postgraduate Studies and Research (CPSR), Infrastructure University Kuala Lumpur (IUKL). She obtained her PhD in Intercultural Communication at the University Putra Malaysia. She specializes in Intercultural Communication, Quantitative Data Analysis, Human Communication and Small Group Communication.

Email: norzita@iukl.edu.my 


\section{REFERENCES}

Alghamdi, A., Karpinski, A. C., Lepp, A., \& Barkley, J. (2020). Online and face-to-face classroom multitasking and academic performance: Moderated mediation with self-efficacy for self-regulated learning and gender. Computers in Human Behavior, 102, 214-222.

Anderson, P. (2016). Web 2.0 and beyond: Principles and technologies. Chapman and Hall/CRC.

Andreassen, C. S., Pallesen, S., \& Griffiths, M. D. (2017). The relationship between addictive use of social media, narcissism, and self-esteem: Findings from a large national survey. Addictive Behaviors, 64, 287-293.

Arbona, C. (2016). Ethnic minority status stress, self-efficacy, and persistence intentions among Hispanic college women: A moderation analysis. Journal of Psychology and Behavioral Science, 4(1), 11-22.

Bandura, A. (2001). Social cognitive theory: An agentic perspective. Annual review of psychology, 52(1), 1-26.

Baumgartner, S., E., Weeda, W., D., Heijden, L., v-d., \& Huizinga, M. (2014). The relationship between media multitasking and executive function in early adolescents. The Journal of Early Adolescence, 34(8), 1120-1144.

Bellur, S., Nowak, K. L., \& Hull, K. S. (2015). Make it our time: In class multitaskers have lower academic performance. Computers in Human Behavior, 53, 63-70.

Boahene, K. O., Fang, J., \& Sampong, F. (2019). Social media usage and tertiary students' academic performance: Examining the influences of academic self-efficacy and innovation characteristics. Sustainability, 11(8), 2431.

Bui, H. T., So, K. K. F., Kwek, A., \& Rynne, J. (2017). The impacts of self-efficacy on academic performance: An investigation of domestic and international undergraduate students in hospitality and tourism. Journal of Hospitality, Leisure, Sport \& Tourism Education, 20, 47-54. https://doi.org/10.1016/i.jhlste.2017.02.002

Cain, M. K., Zhang, Z., \& Yuan, K.-H. (2017). Univariate and multivariate skewness and kurtosis for measuring nonnormality: Prevalence, influence, and estimation. Behaviour Research Methods, 49(5), 1716-1735.

Carrier, L., M., Rosen, L., D., Cheever, N., A., \& Lim, A., F. (2015). Causes, effects, and practicalities of everyday multitasking. Developmental Review, 35, 64-78.

Chang, Y. (2017). Why do young people multitask with multiple media? Explicating the relationships among sensation seeking, needs, and media multitasking behavior. Media Psychology, 20(4), 685-703.

Chin, W. W. (2010). How to write up and report PLS analyses. In Vinzi, V. E., Chin, W. W., Henseler, J., \& Wang, H. (Eds), Handbook of partial least squares. Springer.

David, P., Kim, J.-H., Brickman, J. S., Ran, W., \& Curtis, C. M. (2015). Mobile phone distraction while studying. New Media \& Society, 17(10), 1661-1679.

Dindar, M., \& Akbulut, Y. (2016). Effects of multitasking on retention and topic interest. Learning and Instruction, 41, 94-105.

Drago, A., Rheinheimer, D. C., \& Detweiler, T. N. (2018). Effects of locus of control, academic self-efficacy, and tutoring on academic performance. Journal of College Student Retention: Research, Theory \& Practice, 19(4), 433-451.

Hair, J. F., Risher, J. J., Sarstedt, M., \& Ringle. C. M. (2019). When to use and how to report the results of PLS-SEM. European Business Review, 31(1), 2-24. 
Hassell, M., \& Sukalich, M. (2016). A deeper look into the complex relationship between social media use and academic outcomes and attitudes. Information Research, 21(4), 1-18.

Harman, H. H. (1976). Modern factor analysis. University of Chicago Press.

Jenkins-Guarnieri, M. A., Wright, S. L., \& Johnson, B. (2013). Development and validation of a social media use integration scale. Psychology of popular media culture, 2(1), 38-50.

Joyce, T., B. Y., \& Yates S., M. (2007). A Rasch analysis of the academic self-concept questionnaire. International Education Journal, 8(2), 470-484.

Kaya, T., \& Bicen, H. (2016). The effects of social media on students' behaviors: Facebook as a case study. Computers in Human Behavior, 59, 374-379.

Kolo, A. G., Jaafar, W. M., \& Ahmad, N. B. (2017). Relationship between academic self-efficacy believed of college students and academic performance. IOSR Journal of Humanities and Social Science (IOSR-JHSS), 22(1), 75-80.

Krejcie, R. V., \& Morgan, D., W. (1970). Determining sample for research activities. Educational and Psychological Measurement, 30(3), 607-610.

Lambić, D. (2016). Correlation between Facebook use for educational purposes and academic performance of students. Computers in Human Behavior, 61, 313-320.

Lau, W. W. (2017). Effects of social media usage and social media multitasking on the academic performance of university students. Computers in Human Behavior, 68, 286291.

Liu, D., Kirschner, P. A., \& Karpinski, A. C. (2017). A meta-analysis of the relationship of academic performance and social network site use among adolescents and young adults. Computers in Human Behavior, 77, 148-157.

Liu, W. C., Wang, C. K. J., \& Parkins, E. J. (2005). A longitudinal study of students' academic self-concept in a streamed setting: The Singapore context. British Journal of Educational Psychology, 75(4), 567-586.

Malaysian Communications and Multimedia Commission (MCMC). (2017). Statistical brief number fifteen: Internet users survey 2017.

Martha, K. (2010). Factors affecting academic performance of undergraduate students at Uganda Christian University. Caribbean Teaching Scholar, 1(2), 79-92.

Morissan. (2020). The influence of smartphone use on academic performance among Indonesian university students. Jurnal Komunikasi: Malaysian Journal of Communication, 36(3), 84-101.

Muhammad, M., Hasan, H., Jalil, A. Z. A., Azman, N. A. M., Ahmad, R. P. N. R., \& Zin, M. M. (2020). Electronic media studies in upgrading learning and teaching: Effective strategy provided by RTM. Jurnal Komunikasi: Malaysian Journal of Communication, 36(3), 374-389.

Peng, D. X. \& Lai, F. (2012). Using partial least squares in operations management research: A practical guideline and summary of past research. Journal of Operations Management, 30(6), 467-480.

Podsakoff, P., M., MacKenzie, S., B., Lee, J., Y., \& Podsakoff, N., P. (2003). Common method biases in behavioral research: A critical review of the literature and recommended remedies. Journal of Applied Psychology, 88(5), 879-903.

Raplh, B., C., W., Thomson, D., R., Cheyne, J., A., \& Smilek, D. (2013). Media multitasking and failure of attention in everyday life. Psychological Research, 78, 661-669. 
Rashid, J. A., Aziz, A. A., Rahman, A. A., Saaid, S. A., \& Ahmad, Z. (2020). The influence of mobile phone addiction on academic performance among teenagers. Jurnal Komunikasi: Malaysian Journal of Communication, 36(3), 409-424.

Ross, M., Perkins, H., \& Bodey, K. (2016). Academic motivation and information literacy selfefficacy: The importance of a simple desire to know. Library \& Information Science Research, 38(1), 2-9. https://doi.org/10.1016/i.lisr.2016.01.002

Roy, J. (2011). Impact of school finance reform on resource equalization and academic performance: Evidence from Michigan. Education Finance and Policy, 6(2), 137-167.

Salvucci, D. D., \& Taatgen, N. A. (2008). Threaded cognition: An integrated theory of concurrent multitasking. Psychological Review, 115(1), 101-130.

Schaufeli, W. B., Martinez, I. M., Pinto, A. M., Salanova, M., \& Bakker, A. B. (2002). Burnout and engagement in university students: A cross-national study. Journal of Cross-Cultural Psychology, 33(5), 464-481.

Sekaran, U., \& Bougie, R. (2011). Business research methods: A skill-building approach. John Wiley \& Sons Ltd.

$\mathrm{Wu}$, J. Y. (2017). The indirect relatonship of media multitasking self-efficacy on learning performance within the personal learning environment: implications from the mechanism of perceived attention problems and self-regulation strategies. Computers \& Education, 106, 56-72.

Xu, S., Wang, Z., \& David, P. (2016). Media multitasking and well-being of university students. Computers in Human Behavior, 55, 242-250. http://doi.org/10.1016/j.chb.2015.08.040

You, J., W. (2018). Testing the three-way interaction effect of academic stress, academic selfefficacy, and task value on persistence in learning among Korean college students. Higher Education: The International Journal of Higher Education Research 7(5), 769935.

Zhen, R., Liu, R. D., Ding, Y., Wang, J., Liu, Y., \& Xu, L. (2017). The mediating roles of academic self-efficacy and academic emotions in the relation between basic psychological needs satisfaction and learning engagement among Chinese adolescent students. Learning and Individual Differences, 54, 210-216. 